\title{
COVID-19: A learning moment for patients and health professionals
}

\author{
Stefano Leccardi \\ Cuneo General Hospital, Boves (CN), Italy
}

\begin{abstract}
A hospital physician from Northern Italy describes his own experience as caregiver of COVID-19 patients and as a patient himself who required treatment in urgent care. From this experience he learned that an untapped reserve of human solidarity exists in a team of caregivers in the midst of a crisis where they find an unsuspected shared energy. He never would have believed to be able to work long hours patiently and without sleep until he was challenged by the demands of the COVID crisis. As such, he discovers that to be effective the team leader should lead by example rather than by commandments! His experience as a patient allowed him to face his own mortality, to learn that healing rather than cure is the ultimate goal of caregiving.
\end{abstract}

\section{Introduction}

The COVID-19 epidemic presents multiple and unexpected challenges to Western society, ${ }^{1}$ not just to the medical system. It caused a severe economic downturn that included joblessness. The lockdown of entire cities and countries overtaxed the emotional reserve of the population and restricted the possibility of social exchanges and emotional support.

From a medical standpoint the most urgent needs included proper isolation procedures, increased availability of intensive care, development of medications and vaccines. Equally important was the health maintenance of health professionals who are the frontline soldiers in the war against coronavirus. Because of exposure they are at higher risk of infection than the general population. Because of their work demands they are at increased risk of emotional burn out. ${ }^{2}$

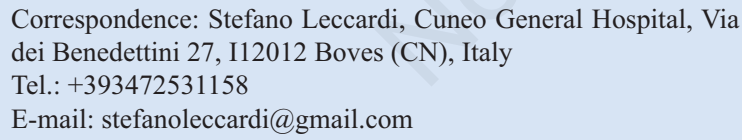

Key words: COVID-19; healing; urgent care; solidarity; nonverbal communication; patienthood.

Conflict of interest: The author declares no conflict of interest.

Ethics approval: Not applicable.

Received for publication: 19 October 2020.

Accepted for publication: 4 December 2020.

This work is licensed under a Creative Commons Attribution NonCommercial 4.0 License (CC BY-NC 4.0).

${ }^{\circ}$ Copyright: the Author(s), 2021

Licensee PAGEPress, Italy

Qualitative Research in Medicine \& Healthcare 2021; 5:9688

doi:10.4081/qrmh.2021.9688
Several studies have already explored these issues with traditional research methodology. As necessary as these studies are, they cannot substitute for the unique observations derived from lived experience of those personally affected as practitioners and patients. As a physician who has worked with COVID patients, and has been close to death from a COVID infection I bear witness to the lessons I learned from this experience with my colleagues.

I learned that a medical crisis unveils unsuspected resources of human solidarity and professional energy. An effective leader needs to harness and exploit these resources. To do so he/she should behave as a role model rather than as a commander.

As a patient on the brink of death I learned that a serious disease represents a unique opportunity to explore the scope of one's humanity. In particular I learned that healing is always possible even when cure is out of reach and that healing should be the ultimate goal of medical care.

\section{Case Report}

A few words of introduction. I work in an Internal Medicine ward in the Cuneo General Hospital, and I love my job. I never conceived of become anything but a doctor and to do anything else but to follow my dad's footsteps. As a child I could hardly wait to grow up and come home to share with my spouse and my children the stories from the hospital. "Vincenza went home today on her own two feet, smiling surrounded by smiling parents and smiling sisters. The last lumbar tap was negative. I really believe she may be cured. This morning, before her family arrived she asked me in private if she could French kiss her boyfriend without risk to him!" or " You know, we think of death as a definitive loss, but today I learned that death may be a memorable event, like a birth or a wedding. Today an old farmer died surrounded by his spouse and seven children: all of them received communion. The old man could hardly talk but I heard him whispering 
"That is the way I want you to remember my death, as the moment when faith brought together our family, when you could witness that I entered eternity." How much wisdom could faith bring to a person who could barely read and write." When I heard these stories from my dad I felt attracted to medicine, by the privilege to access other people's intimacy, to share their joy and grief. I felt endowed with the mission to continue the mission of my father, who had been Chief of Internal Medicine for forty years in a major hospital almost until his death.

As most physicians of my generation I did pursue a subspecialty. For almost ten years I had worked as a pulmonary consultant in critical care. I felt comfortable in manning the breathing machines, but in my heart of heart I did long for direct contact with the patients. Indeed I think that the machines burned me out. I got tired of looking at numbers and screens and dials. Dad seemed to enlighten with his smile each hospital room he visited. I wanted to feel like that sun myself. When the position of attending became available I felt that my professional dream had been realized.

The practice of internal medicine enlarges the scope of your medical knowledge. It gives you a feeling for the seriousness of different diseases, for the impact they may have on the patients and their family. It fosters cooperation with the hospital staff and promotes the spirit of a team. Most of all it allows you to recognize the influence of patient individuality on medical outcome. I learned that the disease is a theoretical construct necessary to inform our care, but the only reality is the patient in front of you. Your ability to deal with personal problems may be as important as the prescription of the correct investigation or medication. ${ }^{3,4}$

The setting of my practice is very relevant to my history. Cuneo is the capital of a province in the Northern Italian region of Piemonte. It is surrounded by mountains and presents difficult access when compared with other towns of the same importance. To reach Cuneo by railway from Alessandria a little more than 100 kilometers away you need to change train once and it may take as long as four hours. By car you have to negotiate the traffic and the traffic lights of multiple villages as no highway reaches Cuneo.

One may think that the personality of the citizens has been molded by the geographic isolation. Hard working people, of few words, they are extremely fair in business transactions and express mutual solidarity with actions rather than with words. I barely exchanged more than good morning and good evening with the lady that collected the dirty cloths of the patients, yet she was crying at my dad's funeral. I learned from some acquaintances that she was very grateful to me for being invited every year to the Christmas party at my house, even if she never showed up out of shyness. The people of Cuneo may appear suspicious of anybody perceived as a foreigner as an intruder threatening their routine. In most cases I believe we are dealing with timidity, with the fear not to understand the expectations of new people and not to live up to those expectations. For the same reason the inhabitants of Cuneo and its province feel isolated from the rest of the country, and this feeling of isolation inspires a false sense of security from the threats of the outside world.

Few years ago, an old friend, Amedeo Capetti M.D., proudly announced to me that a patient affected by SARS, a lethal infection from Asia, had left his ward alive and well. I shared his pride. I had trained years before in respiratory disease at the same Sacco hospital in Milan. At the mean time I looked at SARS as an exotic disease I would have never had an occasion to treat in Cuneo. Little did I know then that in a few years my very hospital would have been inundated by coronavirus patients. And I am proud to say that this experience reinforced my faith in human creativity and solidarity as no other experience in my twenty-five years of medical practice.

Since its beginning the coronavirus infection was rampant in Lombardy, the region adjacent to Piemonte. Every night the television was broadcasting the parade of death carts, transporting the dead to the Bergamo cemetery. It was a devastating spectacle that evoked the image of plague epidemics from centuries ago. Something we were all but certain we would have never witnessed in our times. For me it was also personal. In that very cemetery we had laid to rest few months before my younger brother, a psychiatrist who had succumbed to a year long very painful battle with melanoma. Any burial renewed my pain. Yet a general feeling prevailed that our community may have been preserved from COVID-19.

On a Sunday we heard that two Chinese citizens had been admitted to our hospital with symptoms consistent with COVID. Everybody was relieved as we learned that the diagnostic test was negative. Maybe there was indeed a magic barrier protecting our province from nocuous external influences. After all the two patients were not even resident of our province. Yet deep down everybody knew that the battle with coronavirus was unavoidable and had been only delayed.

One day a new wall of sheetrock rose suddenly and unexpectedly between the internal medicine and the geriatric wards. It was the first tangible reminder that the enemy was closing on us. Our ward was designed to receive the overflow of COVID patients and all contacts with areas hosting patients vulnerable to the infection had to be rescinded. Thanks to my training in respiratory diseases I was assigned to the team that would have cared for COVID patients.

I faced a revolving door: I had to decide right away whether to accept my new role or to decline it. Long and unpredictable working hours would have kept me away from my spouse and my daughter, that I loved more than anybody else in this world. Worse, I might have carried the infection to them from the hospital. They might have gotten sick. God forbid they might even have died. At the 
meantime I was overwhelmed by the compulsion to pay back the society for a very rich and enjoyable life. I had so many reasons to be grateful! My wife and I had shared an awesome adventure. I thought of the adoption of our child from Columbia, who came as a joyful and unexpected surprise after many years of vain hope. I thought of my work where I had so many opportunities to witness the healing of the souls if not of the body. I thought of the friends that had supported with enthusiasm my journey through life. There have been difficulties, there have even been tragedies in my life, but thanks to my family and friends I have been able to live each one of them as learning moments, as occasions to embrace with awe and gratitude the mystery of life. All people I had loved, even those who had died, gathered around me and smiled: "to refuse this service is just impossible!" and with a smile I faced this new commitment.

The COVID journey began with the beginning of March.

The very first challenge was to establish certain diagnostic criteria. The patient was febrile, lethargic, fatigued. Were we dealing with a common viral infection or with COVID? Let's see: his son used to work in Milan, and he might have contracted COVID from him.... But the laboratory test was negative. How much might we have trusted the laboratory?

Our ward became able to face COVID thanks to major restructuration. The main concern was the Oxygen administration that without proper adjustment might have soon overwhelmed our capacity. The renovation allowed us to administer Continuous Positive Airway Pressure (CPAP) at the same time to all patients in the ward. A professional of Emergency Medicine came to refresh our knowledge of CPAP and of the High Flow Nasal Cannula (HFNC) system. Plenty of meetings with the infectious disease specialists took place in order to ascertain what might have been the most effective approach to COVID while the evidence for an effective treatment was all but nonexistent.

While these arrangements took place the mood in the ward was strange. A number of people, especially nurses started crying unexpectedly and without obvious reason, while other team members endeavored to console them. The alternation of tears and laughter was uncontrolled and inexplicable. Maybe this is the mood of soldiers waiting for an incoming battle. The military metaphor was supported by the small mustache of the chief of infectious disease that reminded me of a colonel in charge of a regiment, by the fact that I served in the military in that very town, and by the restructuration that made all of us feel like soldiers in a trench or as pilots ready for an urgent and dangerous mission.

Finally, the first real COVID patients arrived. The first ones were visitors from other places (Torino, Savigliano). Maybe that the invisible barrier isolating Cuneo from the rest of the world was still working. Vain hope! The citizens of Cuneo got sick as well! The majority were older individuals who died in a few days. But even young people were affected by the virus. I remember a forty-year old man who required artificial ventilation and happily survived. And even a nurse of our hospital in her twenties contracted the disease in those initial days.

The hospital looked more and more as a field hospital in the course of a battle. There were no regular working schedules. Our duty was to continue towork day and night with as few pauses as possible. In the very first night we had three admissions and two deaths. No time to rest. Bury the dead and care for more wounded! As soldiers we were asked to wear a protective uniform that made our movement all but more difficult. An anti-infectious gown made the heat almost unbearable. Waterproof eyeglasses became immediately clouded because of the protective mask. Clouded glasses and presbyopia hindered the performance of any procedure, such as drawing arterial blood gases. In lieu of the glasses we welcomed that visor that made us look like gardeners mowing the grass

Believe it or not, but the progression of the epidemics was also associated with heartening and rewarding experiences. Our nurse manager was a middle age mother of three teenagers married to a high school teacher. The whole family was very fond of mountaineering, a hobby favored by the geography of our area. Let's call her Lucia. She was very proud of how she had been able to balance her family and professional life. Her office walls were literally wallpapered by pictures of her family on the top of mountains.

"Lucia; why you are not out mountain climbing with your family in this wonderful Sunday" I asked surprised to find her at work on a holiday. Her face was made ten year younger by a smile that expressed a newly found peace: "Doctor, my family and I discovered that now our mountains, our adventures are here in the hospital. All our hiking plans have been tabled until the end of the pandemic. And I don't want for you to feel sorry about us. Peter (her husband) and I called a family meeting two nights ago. "Children - I said - your father and I talked it over last night. We are endowed with professions of services to the sick, to the adolescents and their crises. This tragedy is a renewed call for our services. My patients need my time, his students need dad's effort so that they will survive as unscarred as possible this epidemic and won't be left behind in their learning. We ask you to be patient with us if we will spend long hours working. It is time to show to God our gratitude for our riches." The children asked what they could do to help. One volunteered in a food line and the others to take care of the immigrants that live in the tent camp at the outskirts of the city and will be the most vulnerable to the economic consequences of the pandemic.

Lucia spent 18 hours in the ward every day: from 7 to 1 in the morning. She received no extra pay for her dedication to solve timely all the challenges that accrued during the day and that became more and more serious each 
day. She kept working as she tested positive for COVID and fortunately she survived the infection without major illness. She even joked when her husband was admitted to the hospital: "I felt particularly privileged! I am the only wife who can visit her sick spouse!" At that time parental visits had been strictly prohibited. She behaved as an ideal commander in chief should behave. She led her team by role modeling, not by commandments. Lucia did not ask her staff for any extra work but everybody committed to longer hours. A young man just graduated from Nursing school stated: "I have never been so proud of my profession! Indeed, until the epidemics I had the impression to work with disenchanted people trying to conclude with the least effort their turn in the hospital to go back to their lives. Now I discovered that our life is here and I would not choose a different profession for anything in the world."

The example set by Lucia trickled down to the whole hospital personnel, including the physicians. When the mother of one of our colleagues died of unrelated causes and she needed to spend a few days home, we almost competed with each other to take over her duties. She thanked us crying: "The death of mother in the middle of the epidemic allowed me to discover an unsuspected reserve of human solidarity, that may sprout only from a love that remained concealed until the COVID infection permitted its explosion!"

Indeed my colleague stated the most important and lasting lesson I learned from the pandemic. It was a twopronged lesson. First, I did learn that during an emergency one manager can count on a reserve of human solidarity in wait to be exploited. Second, I learned that an emergency allows a person to manifest the best of him/herself, that is an unsuspected capacity of love. As a religious person I could not help feeling that my coworkers had transfigured in front of my eyes as Jesus had done in front Peter John and James. I learned to look at the whole person inside the momentaneous appearance, and I hope this vision will accompany me for the rest of my life.

The phone calls with the patients' relatives were at the meantime heartbreaking and highly rewarding. They called us heroes and saints and expected from us miracles, as if it were dependent from us to be able to cure their dying parents or grandparents. But how can one explain that there is no hope, that the loved one will die?

The situation kept becoming more and more chaotic. At the peak of the infection our 600 bed hospital hosted 140 COVID patients. Part of the Emergency Room and of the recovery room became auxiliary intensive care units. Even with these arrangements the Intensive care beds became insufficient and we became compelled to decide whom we might have helped to survive and whom we might have let die. The department of health mandated that ventilators in short supply be not assigned to individuals 75 and over. It was a reasonable provision because life expectancy declines with age and so the ventilation of younger patients would have been more cost effective, i.e. would have saved more years of life. Also the disease became more aggressive in the aged who were less salvageable even with artificial ventilation. Yet this decision was repulsive to our consciousness of caregivers. Since medical school we were taught that justice is a basic principle of medical ethics and accordingly it would have been unethical to limit a patients' treatment based on age. Also we know from experience how difficult it is to estimate a person life expectancy and for a fact some ninety year old have a more prolonged life expectancy than a forty year old. Last but not least it was difficult to deliver to a sick person the message: "we would have the means to save your life but we can't use them as you are too old to survive."

Fortunately, some patients make the decision simpler. An 80 year-old family physician in respiratory failure told us "When I started to practice medicine the respirators were not available and I promised myself that I would have not allowed anybody to keep me alive with a machine! Colleague, please give me some morphine to relieve my shortness of breath and allow me to go in peace!" Others made it all but impossible, like the 76 year-old engineer who pleaded with us to keep him alive until the birth of his first grandchild! He and his family cursed us when we refused life-saving mechanic ventilation and threatened us with a lawsuit that so far has not materialized.

It is difficult to find a lesson, if any, in being compelled to take actions contrary to our ethical principles. It would be unforgivable to dispute the principles themselves. It is realistic instead to honestly recognize that during an emergency the application of the principles is disputable. We know that similar decisions are taken every day in a field hospital during a battle or a major earthquake. We chose a profession that does not allow us to skirt similar decisions.

In retrospective it may sound like a minor inconvenience, yet I do remember as a major source of frustration all the safety procedures that took so much of our times. It felt like we spent the best part of our days washing our hands, washing them again every time the gloves broke, in delivering mutual advice on how to wear correctly the gown or following the cumbersome disinfection procedures at the exit from each room. Surgeons have to do it every time they enter the operating room, that is three or four times a day for three or four days a week. We were compelled to do it at least twenty times a day and every day. It was counterintuitive to think that adherence to guidelines might have been more important than to readjust an endotracheal tube in a patient in respiratory distress. We had to remind us over and over that delay of action might have represented the best course of action.

March $15^{\text {th }}, 2020$. A new chapter in my history of coronavirus. While I was receiving the report of a colleague who had been on call that night, suddenly I started perspiring and felt lightheaded. I could not stand up. I had 
all symptoms of a vasovagal pre-syncope and a nurse got scared. Everything resolved in a couple of minutes. I imputed my malaise to anxiety. My temperature was just 98.9F and I felt reassured. After my shift I took a shower at home and started shivering. Something was definitely wrong.

In the afternoon my temperature was $101.9 \mathrm{~F}$. My spouse and I agreed I should isolate myself in the loft of our house where there was a bed and a private bath. For a few days I had low grade fever that abated with paracetamol, and general malaise. It was time anyway to take a coronavirus test

So, I joined a line of other health professionals waiting to be tested. One more remembrance of the military service when everybody waited in line for being vaccinated. Among them I did recognize one of my dearest friends with my same symptoms, a service chief in complete suit and tie (I could not help thinking of Dante recognizing Caesar fully armed in the antechamber of hell), and a nurse of our ward. When my test turned out negative a number of well-meaning friends sent me their felicitations. But by then I felt sure I was infected, as fever and fatigue did not abate anymore.

When the fever reached and stayed at $103 \mathrm{~F}$ despite all interventions I called the colonel like chief of infectious diseases and he ordered that I be admitted to the hospital. I grabbed the bag packed by my spouse and away I went leaving two women in tear as if I were a mountain soldier leaving for the Russian campaign of World War II.

I was admitted to an isolation room. A chest radiograph was negative for pneumonia, and the test was still negative, but I could not share my friends' joyful relief. I knew I had something very serious. The negative test was not at all a reason for celebrating. It might have prevented the beginning of therapy with Tocilizumab and hydroxychloroquine, drugs that at the time appeared promising. Eventually the CT of the chest showed bilateral pneumonia. I needed to be treated.

After the first administration of tocilizumab the fever waned away! Fantastic. I knew I would have recovered. My enthusiasm was short lived however as many different ominous signs and symptoms had appeared despite the temporary abatement of the fever. I felt unable to eat, an experience all but unknown to me. Indeed, I had been overweight for most of my adult life. And the taste of every grub turned to be salty and bitter. Take the case of coffee. I always liked my coffee unsweetened, but now I would have not been able to drink it without plenty of sugar. The second administration of tocilizumab did not alter my anorexia and fatigue. Indeed as a physician I should have known better and I learned to treasure this new lesson. The course of each disease is to some extent unpredictable because we never know how individual organisms react to the well known pathogen causing the disease. And that is particularly true when we deal with a new pathogen, as it was my case. The disappearance of fever may indicate the beginning of healing, but it may also indicate the loss of bodily defenses and the approaching of death.

On the $24^{\text {th }}$ of March the fever came back with a vengeance, but, even more worrisome, I felt short of breath. The oxygen saturation had dropped to $87 \%$ ! As a specialist in respiratory disease I knew very well what that meant: CPAP if I wanted to stay alive. I started wearing immediately mask and nasal cannulas.

The following morning a good friend, a man of few words and strong sentiments, came to see me and made a grimace. He drew my arterial blood gases and after reading the results told me: "Steve: we have to transfer you to Urgent Medicine" that meant a journey in the ambulance to the other side of the river Stura, where urgent medicine was located. Waiting for the ambulance I started CPAP treatment.

I knew the Urgent Medicine department very well, as I had worked there for ten years and I knew I would have been among friends. I felt a lot of comfort in being surrounded by my previous colleagues. I was only able to see the portion of their face left uncovered by mask and hood. But I recognized their voices, their demeanor, as a dog recognizes the master from his smell. A special surprise occurred when a very authoritative colleague, that in the past had treated me with some condescendence now showed the care of an affectionate brother. With a painless procedure he inserted an intraarterial cannula that prevented the pain of repeated punctures. The feeling of solidarity I had experienced in the previous ward was reproduced in Urgent care. I could not help feeling a member of a well-functioning family animated by love toward a common good.

I wish to add the description of a particular experience, that some people may find irrelevant but for me represented the discovery of beauty. As a middle aged straight man I acknowledge the physical attractiveness of women. In the ward I found all female nurses and volunteers working equally attractive. I could see only their eyes, but I did not need to see anything else to appreciate their beauty. The eyes communicate everything, speak, smile, express sadness and anger. Through the eyes I could appreciate the inner beauty of each human being. Once more, thanks to the mask, I experienced the transfiguration of Jesus.

I doubt I would have tolerated the CPAP torture without the support of my new sisters and brothers. The headset was noisy but more tolerable than I had predicted, if one is not claustrophobic. The pronation, instead, was barely tolerable. I was lying down on my belly six hours each day and the helmet compelled me to stretch my neck in hyper-lordosis, a neck normally as stiff as a glass tube due to cervical arthrosis. But I was comforted because my arterial blood gases were improving consistently thanks to CPAP. Each time the new reading of the blood gases showed improvement the members of the team celebrated with me as if I had just passed a difficult exam. 
After three days the headset was substituted with a more comfortable full face mask and I was allowed to lie on my side, rather than on my belly. I had not slept for four days, kept awake by the ongoing noise and lights in the corridor. Nor did I eat. The benign scolding of my friends because I only tasted few teaspoons of pudding and yogurt did not help. I had no way to try solid food. My stomach felt locked up.

As my respiratory condition was improving, my appetite was coming back and I felt more energetic. The threat of imminent death was fading. I was experiencing was is called the "Lazarus syndrome" that is the recovery from death ${ }^{5-6}$ so named from Jesus' friend Lazarus that Jesus had resurrected from the dead. I realized that I needed urgently to find out who I really was. I might have been nothing more than a casual aggregate of cells and molecules destined to become undone upon my death. Alternatively, my life might have had a unique and standing meaning, something able to survive my corporal death. I had no choice but to chose the second hypothesis, based on the way I had lived so far. I had lived my personal history, my professional activity, my relationships as a relay I had to convey to another runner waiting for me at the end of my life. The experiences I had treasured may survive my brain and may heart as long as they were transmitted by unconditional love. I came to the realization that love can only be unconditional to be love, and as such it must be indestructible. Though I did not know whether I was able of unconditional love, that ancient Greeks called agape, I knew that my lifelong aspiration, underlying all decisions and all actions was to be loved and to love unconditionally.

In this process I was helped by many current friends and also by an erstwhile friend I had not seen in many years. I am talking about Dante Alighieri and his Commedia! In particular I repeated more and more the address of Dante to his old teacher Brunetto Latini. He thanked Brunetto for having taught to him in every moment of his tutoring: "Come l'uom s'eterna" (how the human person may learn to live in eternity). Dante kept whispering in my ear: "look, we are more than biology; we are endowed with an eternal soul" when the spectacle of so many untimely deaths had drained any hope from me. At this pivotal moment I did realize that even if cure is out of reach, healing is always possible. Learning to heal is the highest achievement of a health professional.

I considered a major victory to be weaned from CPAP. Now I was able again to sleep on my own. The insomnia persisted and I begged my colleagues for an early discharge, to no avail. I am glad now that my friends and my own spouse refused to oblige my impatience and to compromise my outcome. This was also a useful experience to share with my patients when they insist to be discharged prematurely.

Finally, I was weaned from oxygen, and started eating. My first full meal included sausage and polenta and I felt as if I were eating at the prestigious and expensive restau- rant Gualtiero Marchesi in Milan. And on April $2^{\text {nd }}$ the ambulance carried me home, twenty lbs. lighter than on admission. My teenage daughter did not use many words to welcome me: "I am happy you are home", but her eyes meant much more than this, they expressed that unconditional love I was yearning for. And thanks to my disease I learned to read eyes! Like Marcel Proust has described in many occasions the eyes reveal the wholeness of the person that keeps becoming richer from life experience and that survives to the ongoing mutations of our external form. I dare to say that the eyes are the gate to eternity.

\section{Discussion and conclusions}

My personal and professional lives are as intertwined as the two helical chains of the DNA. Or at least I love to believe this is the case. It would be futile to try to separate the influences this major crisis had over the different dimensions of my living experience. I know I will keep imprinted in me as long as I live, or at least as long as I am in control of my consciousness, two messages, that have widened my scope of human potential.

There is a major reserve of solidarity within most people, and this resource is largely untapped until a major crisis compels us to work together. To exploit this resource a leader must learn to be a role model for his/her followers. I mentioned as an example Lucia, the nurse manager of our ward who spent long uncompensated hours at work. Stress, sleep and food deprivation did not seem to influence her dedication, and perhaps more important they highlighted her pride to be able to serve. With her example she elicited a kind of joyful competition to serve among staff and physicians. It is important to highlight that the support of her family was paramount to Lucia's endurance. Together with her spouse and her children she has been able to make of the care of the sick a family project that for longer than a year took the place of their mountain excursions. One may object that the majority of workers could not count on such a supportive family. Still most of them appeared inspired by the example of the leader to make of the emergency a family affair. I would not be surprised to learn that this crisis had brought more family lives together than it had disrupted.

This lesson is particularly relevant to our times when the figure of the officer who leads his soldiers in a battle and faces first the enemy fire is all but waned. Today a leader must be a master of technology. As such he/she may not be prepared to face a crisis of the size of the COVID epidemics. Technology would be of no use unless there are individuals willing to risk their well being and their very life in order of delivering life-saving technology. The discovery of a vaccine or an antivirus will save lives only as long as there are lives left to be saved!

Like many of my colleagues I discovered in myself an unexpected reserve of energy that allowed me to work long hours and to help without hesitation a colleague in 
need. Never would I have fathomed to be able to overcome any form of burn out ten years ago when I left my position in urgent medicine because of a hint of burn out. But then I had the leisure to choose what kind of professional activity was more congruous with my personality and with my family life. As I mentioned I was fed up with respiratory technology and with the deaths associated with urgent care. I was longing for the personal interaction with each patient that my beloved father had enjoyed. I was longing to exchange smiles and conversation with patients and staff. I was also longing for enlarge my scope of medicine that in urgent care had been largely limited to the management of machines and numbers. The COVID emergency had all but removed this leisure from my scope. My ability to keep seriously ill people alive was required and endowed me with a mission that could not be delayed nor tempered with. Paradoxically, the lack of choice enabled me to be a physician to my best.

The second message concerns healing and is relevant to all people, not just the health professionals. Mike Clees, a British comedian, declared: "Life is a sexually transmitted terminal disease." This statement rung very true to me as I was facing imminent death. As a physician I have been trained to consider the cure of the disease my primary role. Of course I strived to provide compassionate care to the suffering and the dying; I did cry with the children and the spouses of some of the dead and I went to many funerals. But never before did I feel it was my duty to make sense of death. Indeed, I felt that going there might have been an unwarranted intrusion into the patients' intimacy. At the beginning of the pandemic, when the dead were being discharged unnamed into common tombs, the idea to invest my time in finding the meaning of death appeared nothing less than bizarre. My limited resources should all have been devoted to managing patient and fighting death.

It took my own flirtation with death to realize that if death was the ultimate enemy of our humanity we are all doomed as death in unavoidable. The only way to defeat death is to come to term with it, that is to find a sense to our life, and this process is what we call healing. ${ }^{7}$ In this perspective, while cure is occasionally achievable healing is always achievable and as such it should be the most realistic object of all medical interventions. Health professionals are in a privileged position to foster healing as many of the dying patients ask their caregiver to accompany them to the threshold of death. Having faced death myself I could act as the "wounded healer"4 described by Jung, that is a credible healer, ${ }^{8}$ one who knows what he is talking about. Jung himself represented Jesus as a wounded healer, as he asked from his followers nothing more of what he himself had undergone.

I already declared myself as a Christian of Roman Catholic persuasion, but I would find it repulsive to exploit a patient's anguish to impose my faith on somebody else. Instead I found this approach very effective: I hold my patient's hand and say, "Think of death in this way. If you have a single day to visit Rome, you have two choices: you may get out of the train station and try to pack as many monuments as possible. In the evening you will find yourself extremely tired and probably will have forgotten most of your visit. Or you could go on the top of a hill (Gianicolo, Trinità dei Monti) from where you can embrace in a look the whole city and decide which monuments you really care to see. Then your visit will be meaningful and your impression lasting. Think of proximity of death as that hill that allows you to embrace all of your life and select the moments that have been more meaningful for you and your loved one. From there you can make a distillate of your life. An extract of Bulgarian roses where each drop contains the essence of thousand petals withered century ago."

Of course, every person can and should be a healer, but a health professional who has faced death himself is endowed with a unique credibility, because of his scientific knowledge and of his personal experience. I cannot overrate the discovery of healing both in my personal and professional life. Through healing there are not personal defeats, as any experience perceived as a defeat my be turned into a victory. And the scope of my practice has changed: I will be able to accompany each one of my incurable patients to the threshold of death

And thanks to the protective gears that concealed most of the face and the body of the caregivers, I perfectioned my ability to read eyes. That was also a new experience. In a certain way I felt like the apostles witnessing the transfiguration of Jesus on Mount Tabor. I learned to discover the inner beauty of every souls irrespective of whether the host of that soul is young, old, toll, short, black or white. And I discovered the unconditional love of my daughter as I went back home!

\section{References}

1. Fauci AS, Lane HC, Redfield RR. Covid-19 - Navigating the Uncharted. N Engl J Med. 2020;382:1268-9.

2. Firew T, Sano ED, Lee JW, et al. Protecting the front line: a cross-sectional survey analysis of the occupational factors contributing to healthcare workers' infection and psychological distress during the COVID-19 pandemic in the USA. BMJ Open. 2020;10:e042752.

3. Frank AL. On Becoming a Doctor. Am J Med. 2019; 132:1361.

4. Broyard, Anatole. Intoxicated by My Illness: And Other Writings on Life and Death. Fawcett Columbine, 1992.

5. Brant-Zawadzki M. The Lazarus syndrome: the ethics of evidence-based versus experience-based medicine. Radiology 2012;263:629-32.

6. Hall FM. The Lazarus syndrome and the ethics of evidencebased versus experience-based medicine. Radiology 2012;265:976; author reply 977.

7. Byock IR. The nature of suffering and the nature of opportunity at the end of life. Clin Geriatr Med 1996;12:237-52.

8. Gonzales M, Melton L. The Wounded Healer. J Adv Pract Oncol 2017;8:453-5. 